\title{
COMPUTING INSTALLATION PARAMETERS OF CCTV CAMERAS FOR TRAFFIC SURVEILLANCE
}

\author{
Pratishtha Gupta $^{1}$, Prof. G. N. Purohit ${ }^{2}$, Amrita Dadhich ${ }^{3}$ \\ ${ }^{1}$ Department of Computer Science, Banasthali Vidyapith, Jaipur, India \\ pratishtha11@gmail.com \\ ${ }^{2}$ Department of Computer Science, Banasthali Vidyapith, Newai, Rajasthan, India \\ gn_purohitjaipur@yahoo.co.in \\ ${ }^{3}$ Department of Computer Science, Banasthali Vidyapith, Jaipur, India \\ amrita8288@gmail.com
}

\begin{abstract}
For properly installing CCTV cameras on any intersection point for traffic surveillance, some parameters need to be determined in order to get maximum benefit. The height, angle of placement of the CCTV camera is used to determine the view or the area that the camera will cover with proper resolution. The resolution should not be too high to cover less traffic and should not be too low to cover large but hardly distinguishable traffic.

This paper concerns with computation of the required CCTV installation parameters for the correct placement of CCTV camera. The simulation experiment has been done in ArcGIS to calculate different parameters and compare different computation results, and provide the necessary parametric specifications to install CCTV at a site. Viewshed Analysis is carried out to find the influence of variations in various parameters on the traffic images. Various comparisons are shown and best parameters are presented in results.
\end{abstract}

\section{KEYWORDS}

CCTV, Viewshed Analysis, Google Earth, ArcGIS, Traffic Surveillance

\section{INTRODUCTION}

This document analyses the impact of various CCTV camera installation parameters on the traffic images acquired to cover an optimal length of road for real time traffic signal control. Various CCTV Camera installation parameters include its height, vertical and horizontal orientation, frequency, resolution and focus points of the images being acquired.

This paper is divided into six sections. The second section presents the related work. The third section discusses the technologies used in the experimental study. The fourth section describes the procedure of acquiring the required information. The fifth section presents the simulation experiment and results. The sixth section draws the conclusion.

\section{RELATED WORK}

A lot of work has been done related to Viewshed Analysis as well as Traffic Management System. But both the technologies have not been used together much, i.e. developing a Traffic

DOI : 10.5121/ijcsit.2012.4609 
Management system using Viewshed Analysis and CCTV cameras. There are a number of sources that can help study and work with ArcGIS. One such is by Jonathan Glick [1]. It provides a complete introduction to ArcGIS and its working to the starters. [2] can serve as a useful guide for the making maps, joining different maps on the basis of some common features and modifying maps as needed.

Many papers have been published using the features and applications of Viewshed analysis. [3] is a document that helps in working on Viewshed Analysis and gives a stepwise procedure for that. Vince Green has provided a document that contains a practical viewshed analysis done on a Wind Energy Development site [4]. Lin has given the importance of Viewshed Analysis in Geo-tagging and considered the case of tagging photos on the Internet. This paper visualizes the importance of Viewshed Analysis in analyzing the place where the tagged photo was taken. This shows one more important application of Viewshed Analysis. Aesthetic Quality [5] is a full documentation of how viewshed analysis has been performed on Digital elevation Model of a coastal area. In [6], step-wise process of working on Viewshed Analysis and Cumulative Viewshed analysis has been provided. Many researchers have used Viewshed Analysis for some or the other analysis. Lee et al. [14] worked upon determining least cost paths in a Digital elevation model using Viewshed Analysis. [15] shows the exploration of multiple Viewshed Analysis.

Yung et al. [13] have worked upon calibration techniques of CCTV camera.

To understand working with all features of Google Earth might need some assistance, especially for exploring the features of Google Earth. While talking about the documents, variety of them is available. Andrew Hobby has given a paper regarding the use of Google Earth with ArcMap [7]. El Khamlichi Ahmed et al. In[8] create shapefiles (shp) that should be used in ArcGIS 9.2 for the design of a georeferenced database and the development of thematic maps in (ArcMap) interface in the final result.

Data from Google Earth cannot be used directly into ArcMap. The data from Google Earth is in Keyhole Markup Language (KML) format. To convert the data in a form usable by ArcMap; the Shapefiles, a Toolbox need to be added into ArcMap. This toolbox can be downloaded from [9]. [10] is a help on how to download the toolbox and install it in ArcMap for use, but ArcGIS 9.3 already has this toolbox included in it for conversion from KML file format to a Shapefile.

\section{TECHNOLOGIES}

For the purpose of experiment, the software package ArcGIS version 9.3, the software Google Earth and Viewshed Analysis tool have been used.

\subsection{ArcGIS 9.3}

ArcGIS is a software package developed by Environmental Systems Research Institute (ESRI). It is used by many federal, state and local agencies, as well as educational institutes, businesses throughout the world. It includes desktop, server, mobile, hosted, and online GIS products. There are a number of versions of the software package available like 9.2, 9.0, 8.2 etc. but the current research uses version 9.3 as it has a number of additional characteristics than its previous versions and so is better. The additional characteristics include improved support for creating KML, easier to create high performance web map services, better web security etc. The software package allows us to store, manipulate, analyze and display spatial data. The desktop products allow us to integrate and edit data create new map layers, and author maps. ArcGIS desktop includes a series of scalable products. ArcGIS desktop products include ArcCatalog, ArcScene, ArcMap, ArcGlobe, and ArcReader. 


\subsection{Viewshed Analysis}

A viewshed is an area of land, water, or other environmental element that is visible to the human eye from a fixed vantage point. It can also be defined as an area on terrain surface that is visible from a specific location. The term is used widely in such areas as urban planning, archaeology, and military science. In ArcGIS, Viewshed takes as input a raster file and a file containing observation points and it identifies the cell is the raster that are visible from the observation point. As explained in [11], if only one observation point is present, each cell that can see the observation point is assigned one and the cells that cannot see the observation point are assigned Zero. While in multiple observation points, each cell in the output raster receives a value that indicates how many observer points can be seen from each location.

In ArcGIS 9.3, Viewshed analysis can be calculated from the toolbar of Spatial Analysis or 3D Analysis. In both the toolbars, viewshed function is available in Surface Analysis -> Viewshed.

\subsection{Google Earth}

Google Earth is a virtual globe computer program. Some versions of the software are not freely available and the freely available Google Earth can be easily downloaded. It provides high resolution aerial and satellite imagery. One can identify and mark places and any other data of interest. Google Earth and ArcGIS allow for some inter-compatibility through the use of Keyhole Markup Language (KML) and so Google Earth has been used to get the data for the research. KML, a programming language similar to HTML, was specifically designed to allow spatial map data to be displayed in virtual earth browsers, such as Google Earth. By supporting KML, ArcGIS allows Shapefiles to be converted for viewing in Google Earth. Data imported from Google Earth is in the KML format and can be converted to Shapefiles of ArcGIS.

\section{PROCEDURE OF ACQUIRING THE INFORMATION}

This research uses available resources to get the required information to get a set of parameters that will be used to install CCTV at a traffic surveillance site. The following sections depict the steps for collecting the information.

\subsection{Selection of site}

Rambagh Circle of Jaipur is selected as the site where all the analysis has been done. The circle area is busy one as it connects the main city of Jaipur to the growing part of Jaipur. It has a busy traffic at nearly all time of the day and thus has been chosen for monitoring the effect. One portion of the complete intersection area is taken into account for viewing the effects of placing a CCTV camera with the traffic light's pole.

\subsection{Getting data from Google Earth}

Google Earth provides the complete spatial information of a place and any place on the Earth can be mapped using this application. By downloading it, one can view all the places, their coordinates and any extra information related to the place. Mainly, data from Google Earth is compatible with ArcGIS and thus it has been used. The data taken from Google Earth is in the form of KML (Keyhole Markup Language). KML data can be easily imported into ArcGIS. 
For the research, the place where viewshed analysis needs to be carried out is marked in Google Earth using polygons, and placemarks. The following steps have been followed to collect the data from Google Earth.

i. Rambagh Circle identified on Google Earth and a traffic pole site is marked where we can place the CCTV camera in future. The figure shows the "Pole Point" and has the Latitude $26^{\circ} 53^{\prime} 41.93^{\prime \prime} \mathrm{N}$ and the Longitude $75^{\circ} 48^{\prime} 32.12^{\prime \prime} \mathrm{E}$.

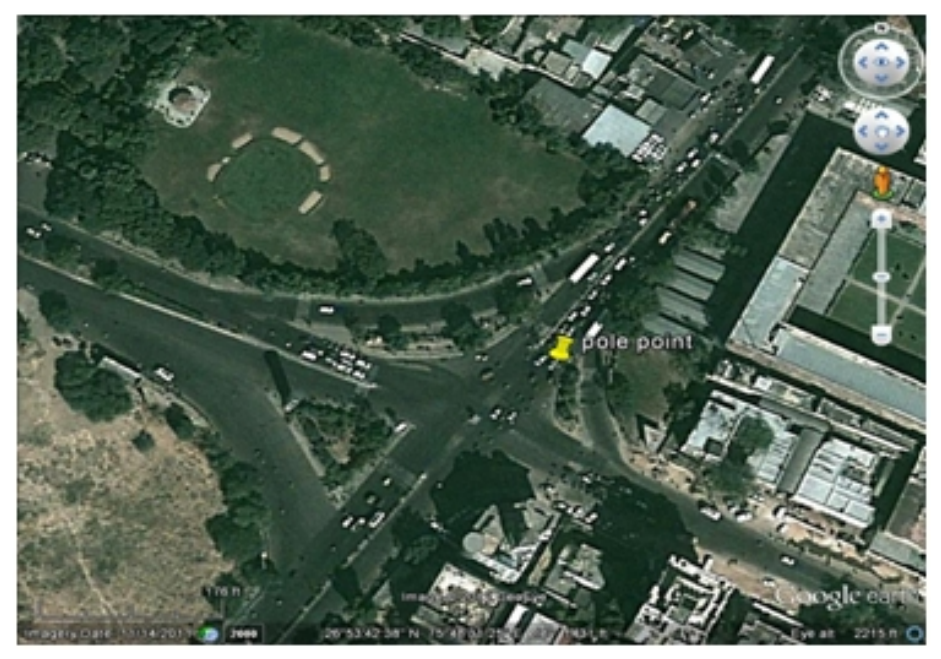

Figure 1 Pole Point

ii. Polygons are drawn to depict the roads surrounding the intersection point. This can be done by right clicking on My Places in Google Earth -> Add-> polygon. A window appears to set the properties of the polygon to be drawn and then by moving the mouse cursor, one can draw a free style polygon or a polygon with defined coordinates. Here, polygons of the major roads surrounding the pole point have been drawn and the figure 6 shows the polygons drawn on the major roads of the intersection points.

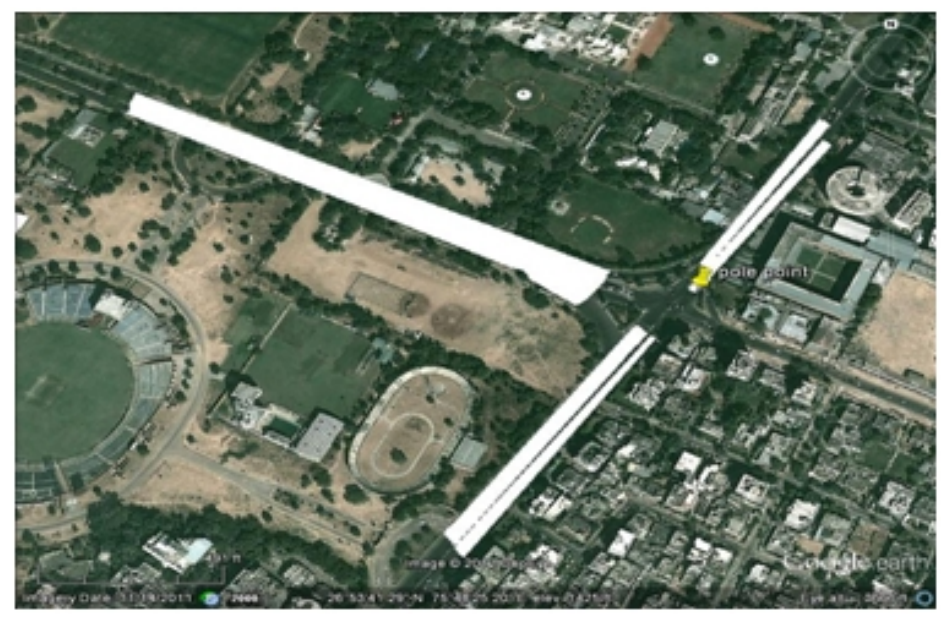

Figure 2: Polygons of the roads drawn

iii. These polygons are saved as KML fileS on the system. 


\subsection{Importing data into ArcGIS 9.3}

Once the KML file has been stored, the data can be used with ArcGIS. ArcMap is used for all the purpose of analyzing and modifying the maps.

i. In ArcMap, the polygon from Google Earth need to be first converted into a shapefile so that any modification can be done. To convert into a shapefile, select the 'Conversion Toolbox' -> 'To Shapefile' -> 'feature class to shapefile'. Specify the needed fields like the Input Feature Class, Type of the Shapefile (Point, Line, and Polygon) and the Output Folder to store the Shapefile. Here, the type of output shapefile is Polygon.

ii. After making the shapefile, import the shapefile into ArcMap by clicking on the 'Add Data' button and browsing for the needed shapefile.

iii. For the purpose of Viewshed Analysis, the Pole Point's Shapefile and the shapefile of the polygons drawn on Google Earth have been imported.

iv. The Polygon Shapefile is converted to a Raster type file as Viewshed cannot be carried on simple shapefiles, it needs a raster dataset. To convert the polygon shapefile into raster dataset, select the 'Conversion Toolbox' -> 'To Raster' -> 'Polygon to Raster' and provide the needed inputs to convert the polygon shapefile into raster type of dataset.

v. Import the raster dataset and the following figure shows the step.

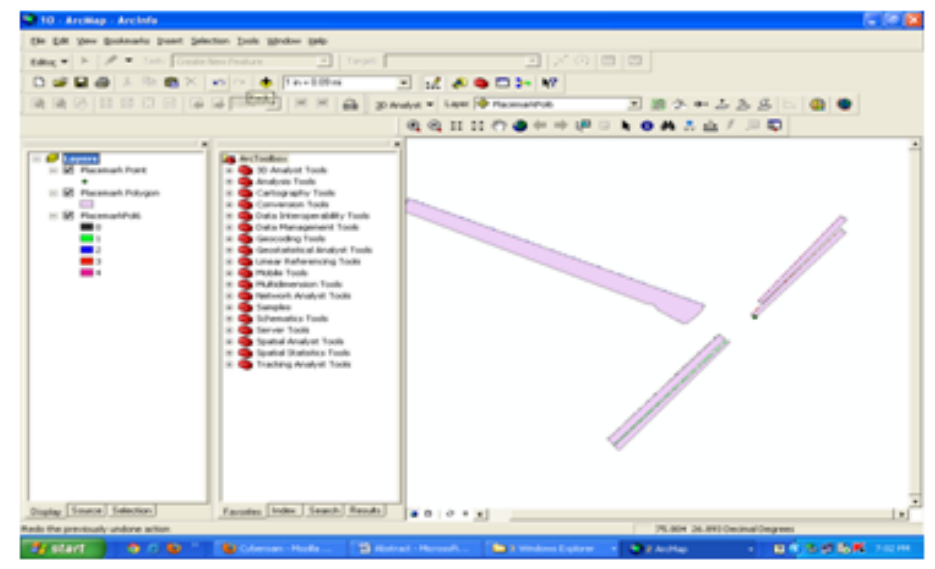

Figure 3: Imported Data

\subsection{Carrying out Viewshed Analysis}

Viewshed analysis shows what cells of the raster are available from the observation point. It hence marks the areas that can be viewed from the specified observation points. It indicates the areas that can be seen from the input polyline or point observation feature.

There are nine optional parameters that need to be taken into account while making a Viewshed. When the NINE parameters are not specified, their default values are taken into account. These nine parameters are:

- SPOT- The surface elevation for observation points and estimated using Bilinear Interpolation.

- OFFSETA- vertical distance to be added to the Z-value of the observation point and has a default value of 1 . 
- OFFSETB- vertical distance to be added to the Z-value of each cell as it is considered for visibility and default value is 0 .

- AZIMUTH1- start of the horizontal angle to limit the scan with the default value $=0$.

- AZIMUTH2-end of the horizontal angle to limit the scan with the default value $=360$.

- VERT1-top of the vertical angle to limit the scan with default value $=90$.

- VERT2- bottom of the vertical angle to limit the scan with default value=-90.

- RADIUS1- inner radius that limits the calculating boundary with the default value $=1$.

- RADIUS2-outer radius that limits the calculating boundary with the default value $=360$.

All these parameters (or the parameters that are needed) are added to the 'Attribute Table' of the point file for the Observation Point. To carry out the Viewshed Analysis, the viewshed window needs to be invoked from 3D analysis (or spatial analysis) toolbar $\rightarrow$ surface analysis -> viewshed. Specify the input raster (here, Placemark Polygon), the input observation features (Placemark Point), and the output raster to calculate the viewshed. The optional parameters can also be changed as needed and the effect of the parameters on the viewshed can be analyzed. Figure 4 shows the viewshed calculated on a part of the intersection area. In viewshed, the GREEN part shows the cells that are visible from the observation point while the RED part shows the parts that are not visible from the observation point.

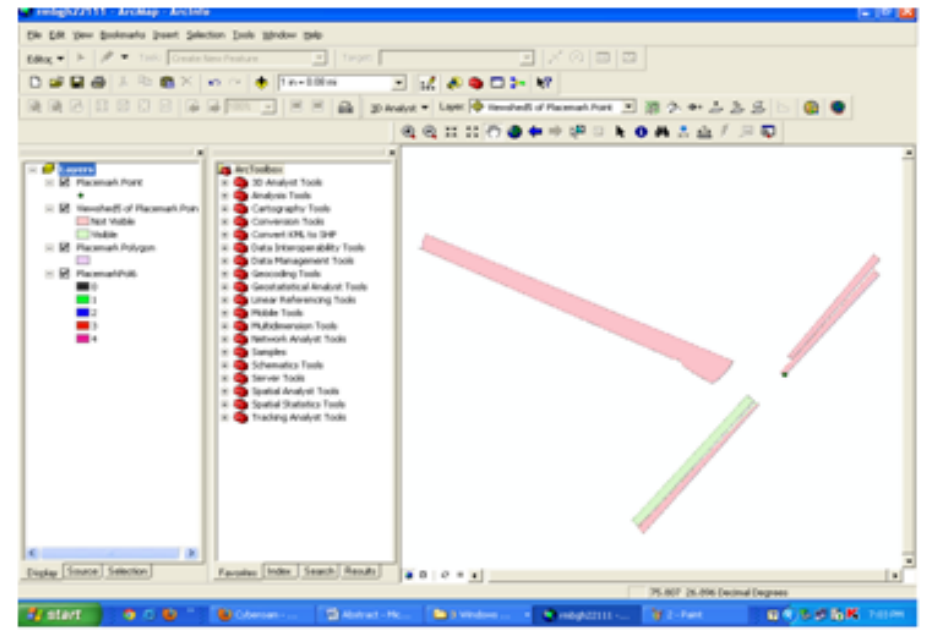

Figure 4: VIEWSHED

Viewshed results in fig. 4 were obtained with the following viewshed parameter values:

\begin{tabular}{ll}
- & OFFSETA=3 \\
- & OFFSETB=1 \\
- & AZIMUTH1=220 \\
- & AZIMUTH2=268 \\
- & VERT1 $1=0$ \\
- & RERT2=90 \\
- & RADIUS1=4 \\
\hline
\end{tabular}




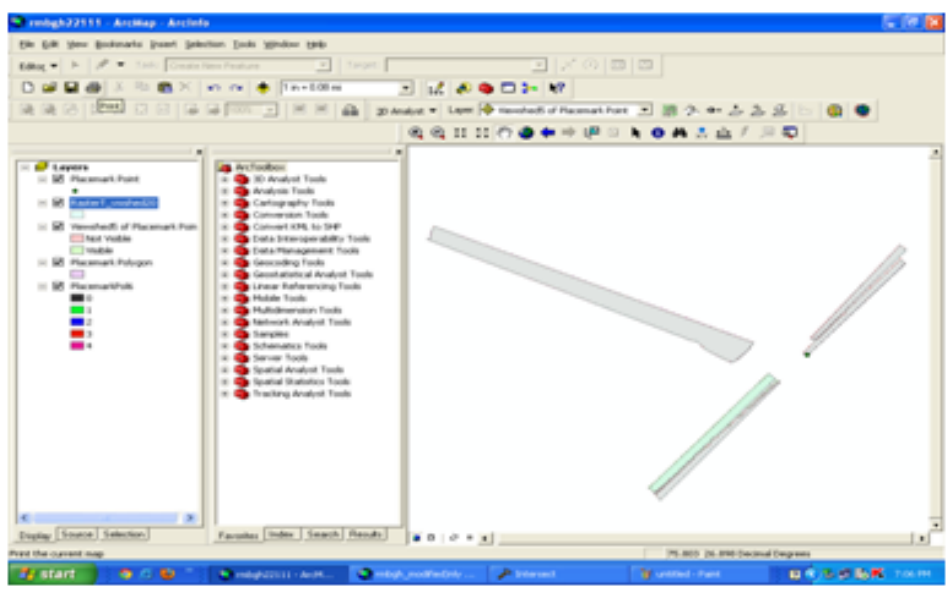

Figure 5: Convert Back to Polygon

After performing viewshed, the results are converted back into polygon type dataset by the toolbox 'Conversion Toolbox' -> 'From Raster' -> 'To Polygon'. Figure 5 shows the result if this conversion. The visible and the not visible parts are shown with different types of polygons.

To view just the viewshed area, some changes need to be inculcated in this file. The transparency of the different layers needs to be changed to view just the viewshed part. The transparency of the viewshed layer is kept intact (0\%) an all the others layers' transparency is changed into $100 \%$. The result comes as shown in the figure 6 . The figure shows the only viewshed of only the needed part.

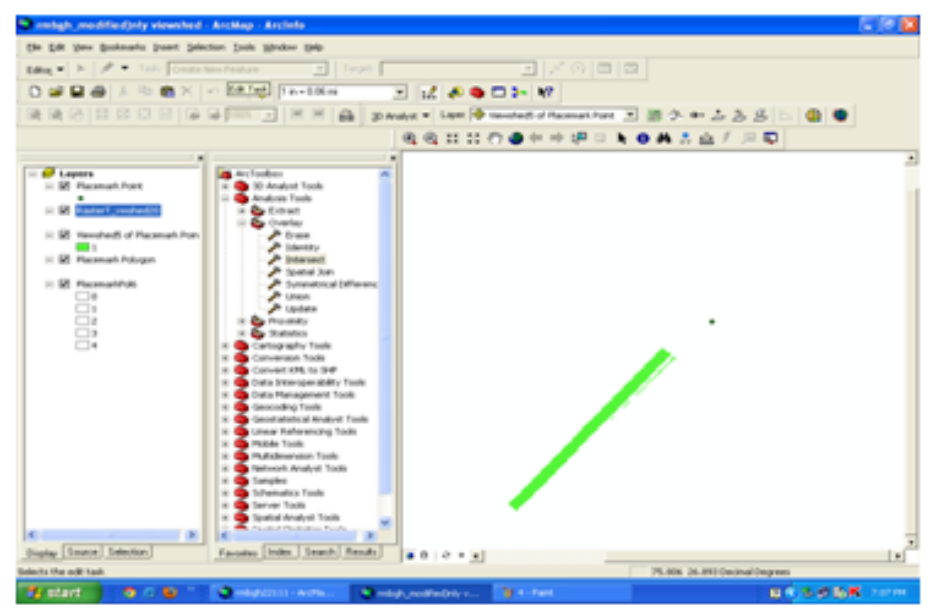

Figure 6

After the viewshed's visible part has been considered, the part need to be divided into small parts to be viewed properly by the CCTV camera. The camera can view the complete portion of the road at a time but cannot work for traffic computation on the complete portion efficiently.

\subsection{Laying the results back to Google Earth}

Google Earth is used to view the results back into the map and determine what portion of the road will be visible from the CCTV's viewpoint at the pole. The CCTV can consider 20 meter portion of the road at a time or it may be 40 meters, 50 meters or the complete road at once. This all 
depends upon the type of the CCTV camera we are using and the system that will be used for traffic computation. The system should be efficiently calculating traffic load from the given snapshot of the intersection area. The calculating power of the system defines the frequency by which CCTV camera takes pictures of the road intersection for computation.

\subsubsection{Considering 20m Area}

Firstly 20 meter portion of the intersection is seen on Google Earth. This is done by making a circular area in Google Earth of radius 20 meter around the Rambagh Circle area. This can be done by specifying the latitude and longitude of the centre as well as by specifying the radius in [12]. This will download a KML file showing a circle around the centre and of the specified radius. The KML file looks like as shown in figure 7 . The red colored circle shows the circle area and the outer circle shows the downloaded KML file of 20 meter radius around the circle area. Figure 7 also shows a polygon drawn. This polygon is in used for intersecting with the viewshed to take out a 20 meter area of the viewshed.

After drawing the polygon between the circle area and the 20 meter radius circle, the polygon is imported to ArcMap's file containing the visible part of the viewshed as shown in figure 6. The polygon file is converted into shapefile as explained before, imported into ArcMap and then intersection tool is invoked (from 'Analysis Tools' -> 'overlay' -> 'intersection'). The two

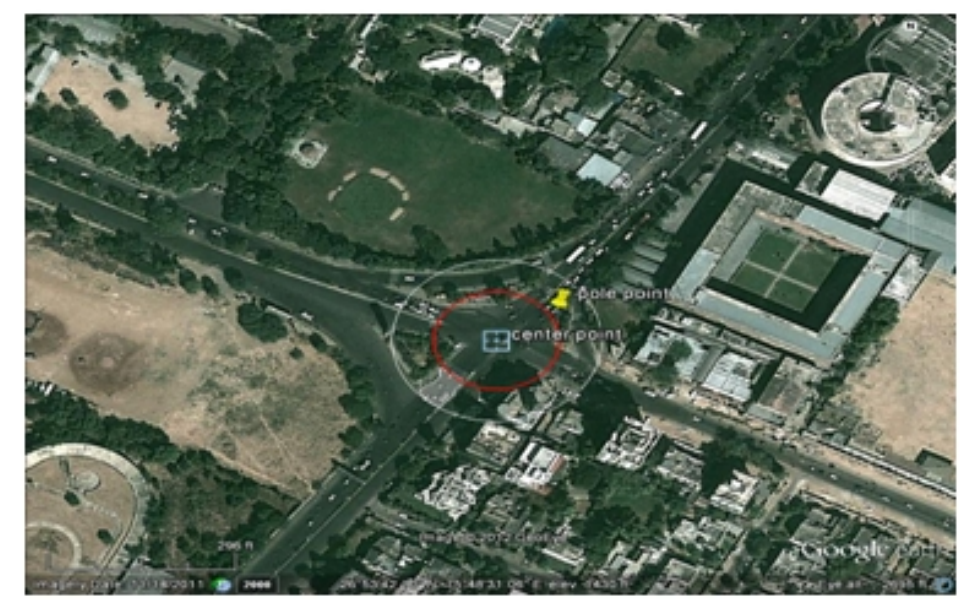

Figure 7: Circle of Radius 20m

layers to be intersected are the constructed polygon of the Viewshed and the polygon constructed from Google Earth and imported as shapefile into the map document. This results into a viewshed portion of just 20 meter length.

This is again converted back into KML file (only the Point file and the resultant intersection). For this, the observation point and the result of intersection function applied are stored in a separate map document. To convert the map into KML invoke the conversion tool from 'Conversion Tool' -> 'To KML' -> 'Map to KML'. This results in a KML file that can be viewed on Google Earth. Figure 8 shows the intersection map laid on Google Earth. 


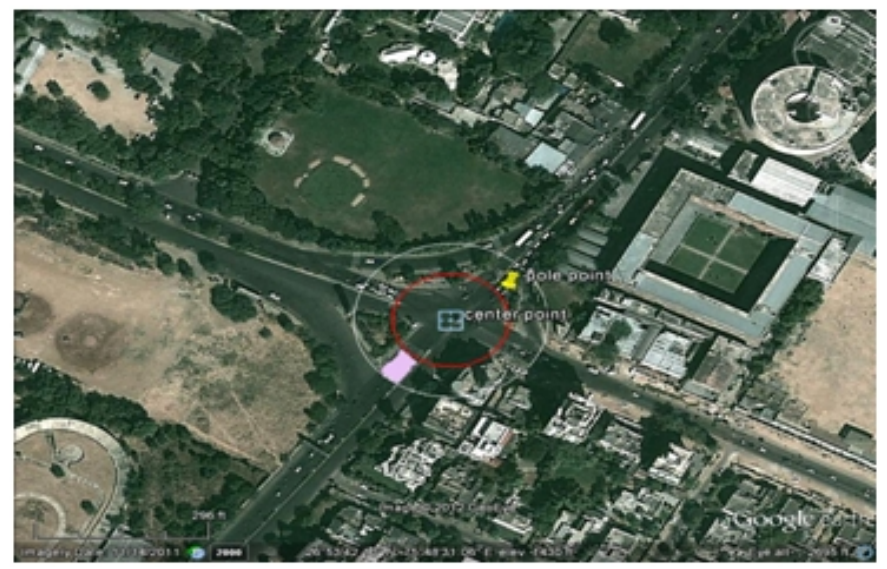

Figure 8: Intersection on Google Earth

Again, Circle from Google Earth is downloaded for intersection and the process is carried for the further area of Viewshed for analysis. The image shows that the CCTV camera will view the indicated portion and traffic computation will be done on that portion at a time. This results in a sequence of images of the visible intersection by the CCTV camera so as to cover the required length of the road. This can be obtained by shifting the focus points of camera. Some images obtained by the intersection of 20 meters are:

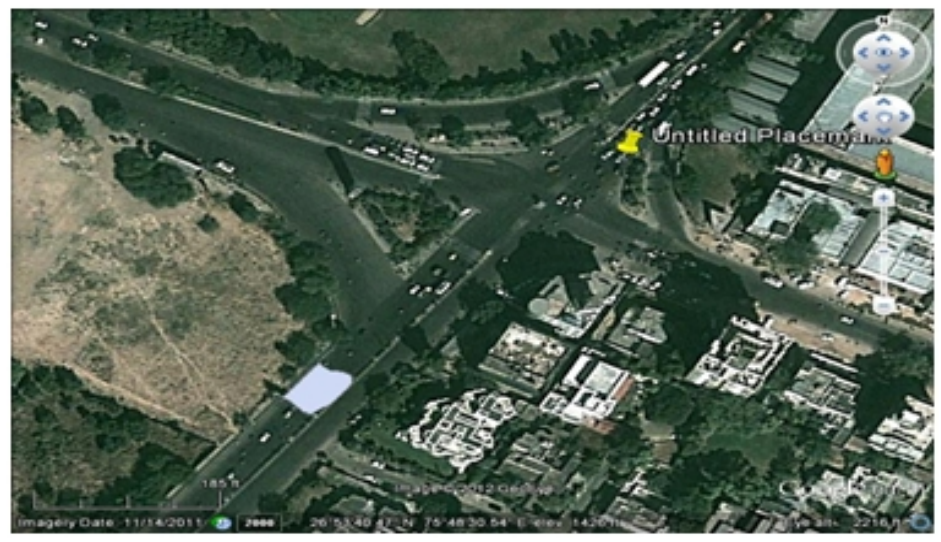

Figure 9

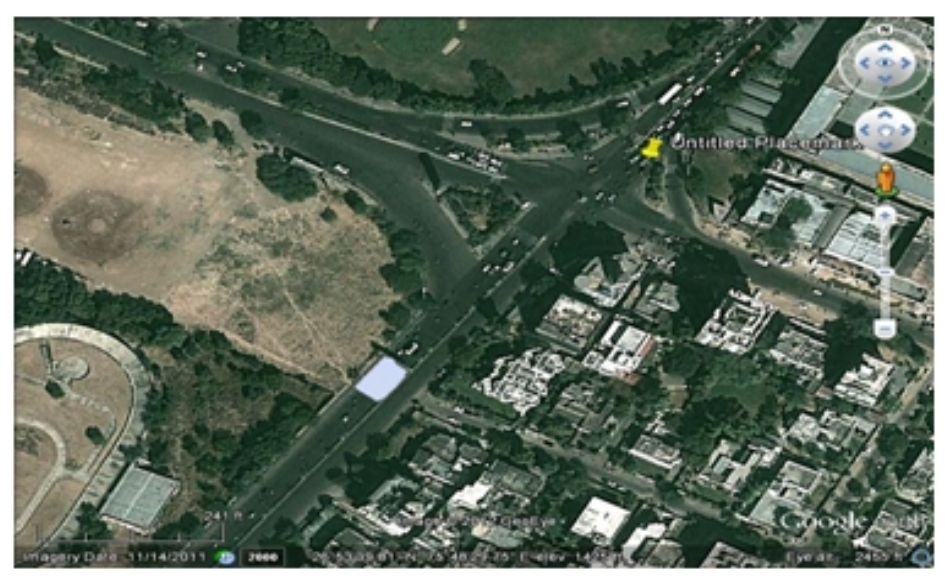

Figure 10 
International Journal of Computer Science \& Information Technology (IJCSIT) Vol 4, No 6, December 2012

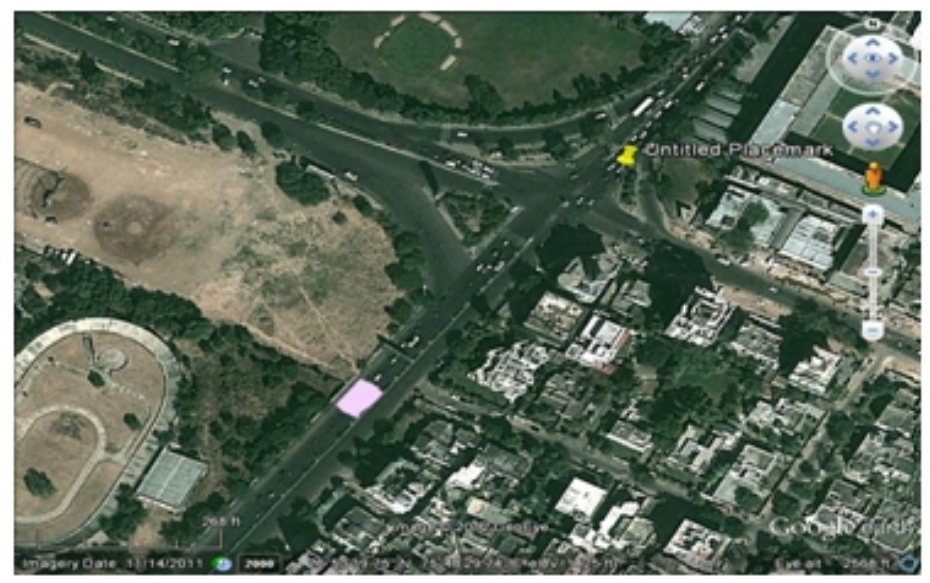

Figure 11

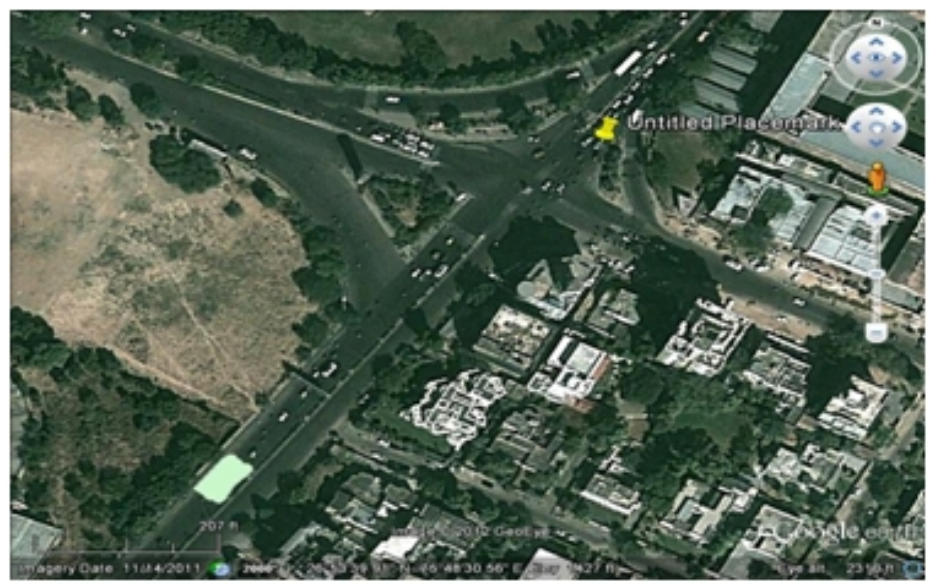

Figure 12

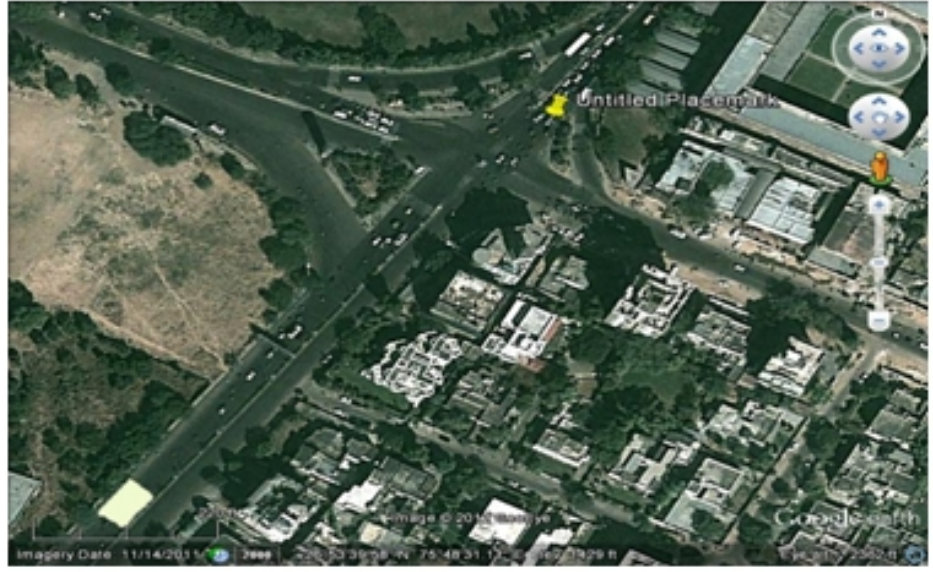

Figure 13 


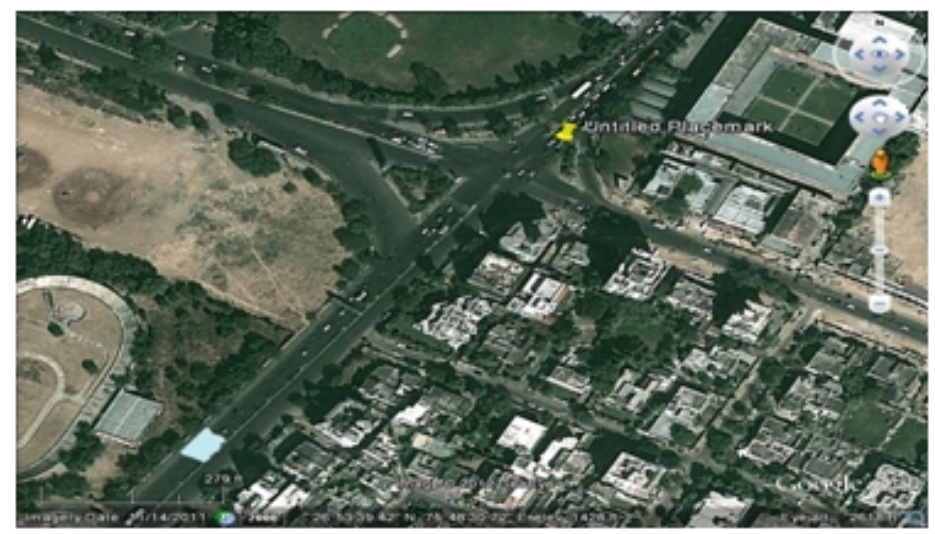

Figure 14

The full portion of the image is as shown in figure 15. It shows the full viewing part of the road with the portions in which the camera will take images. Camera will take 14 photographs and the analysis will be done on them to compute the complete traffic present on that portion of the intersection.

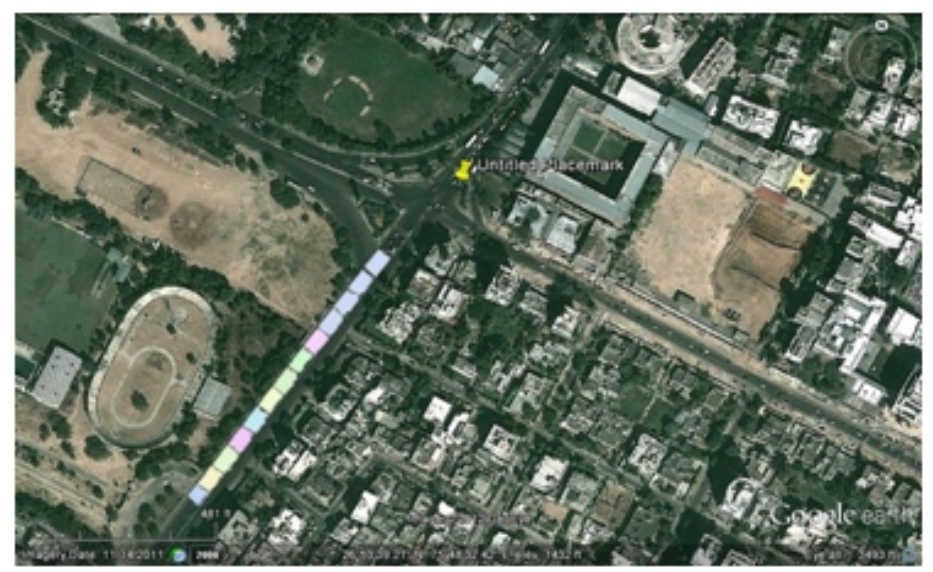

Figure 15

\subsubsection{Considering $30 \mathrm{~m}$ Area}

This time, it is assumed that the CCTV camera covers 30 meter area of the intersection at a time and so the same process is applied and by making intersection polygons of 30 meter length. This is then laid back on Google Earth and so some of the following views can be considered. The figures show that how much area the CCTV will cover at once. 
International Journal of Computer Science \& Information Technology (IJCSIT) Vol 4, No 6, December 2012

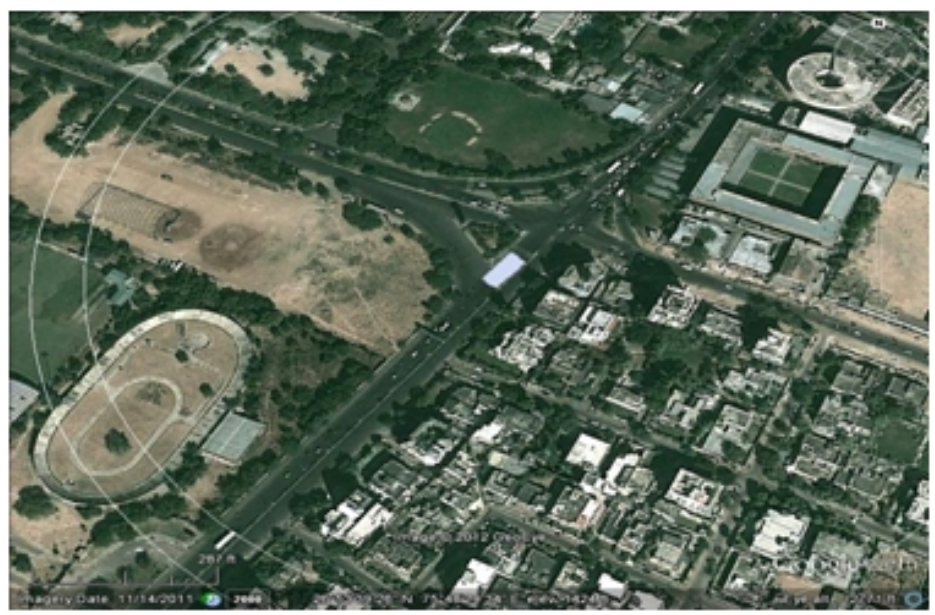

Figure 16

The full coverage is as in figure 19. By covering 30 meter of the intersection road at once, camera will take 9 photographs for processing.

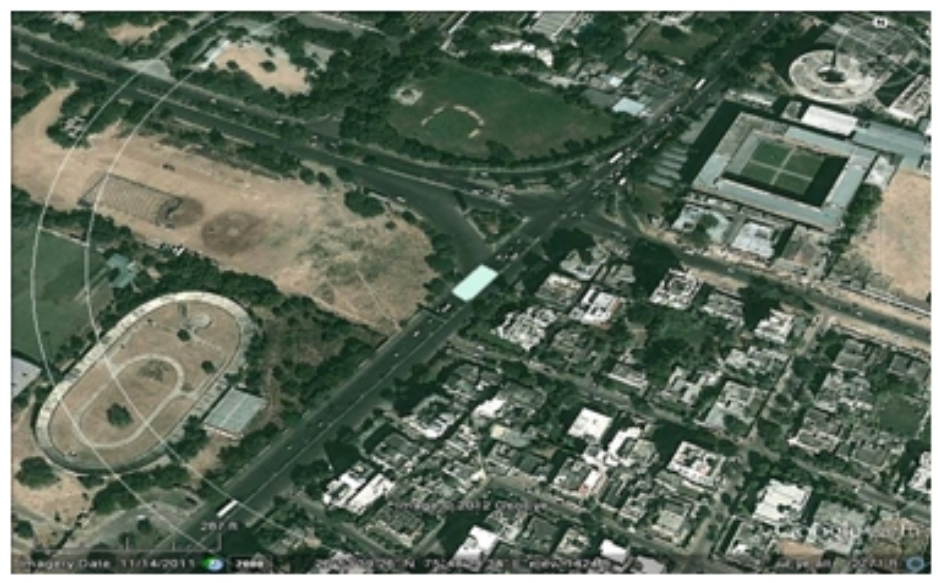

Figure 17

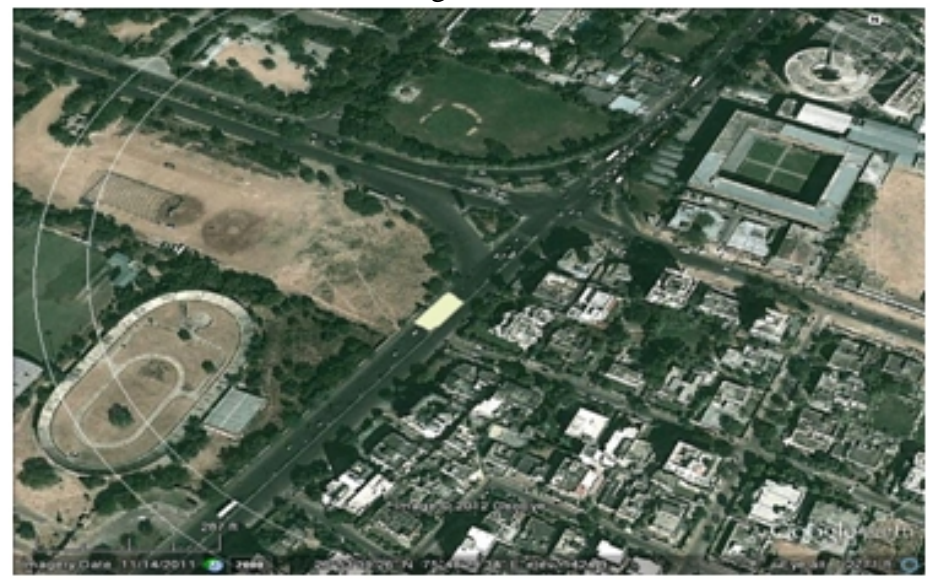

Figure 18 
International Journal of Computer Science \& Information Technology (IJCSIT) Vol 4, No 6, December 2012

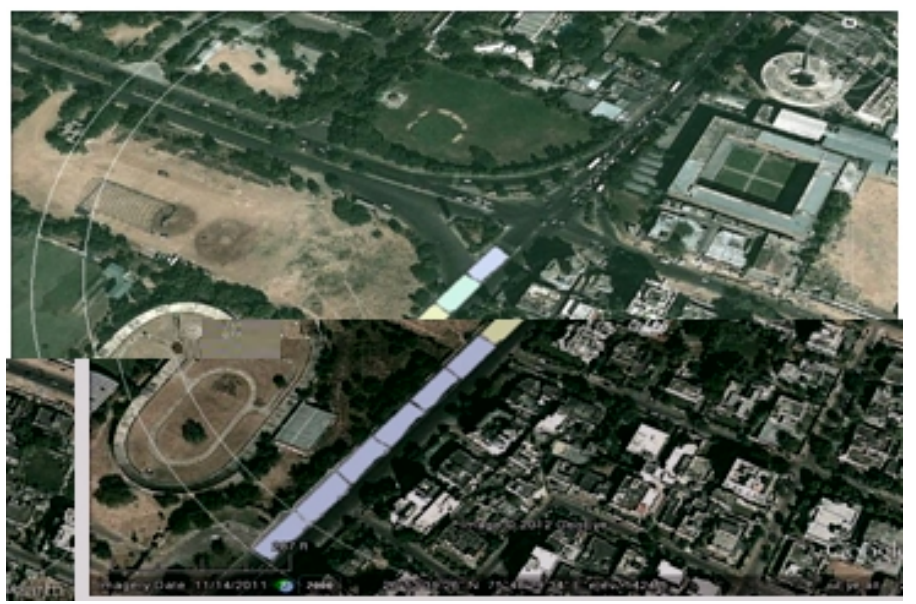

Figure 19

\subsubsection{Considering 40 meter area}

If CCTV camera is taking photographs of 40 meter area, following photographs depict the style in which the areas will be covered.

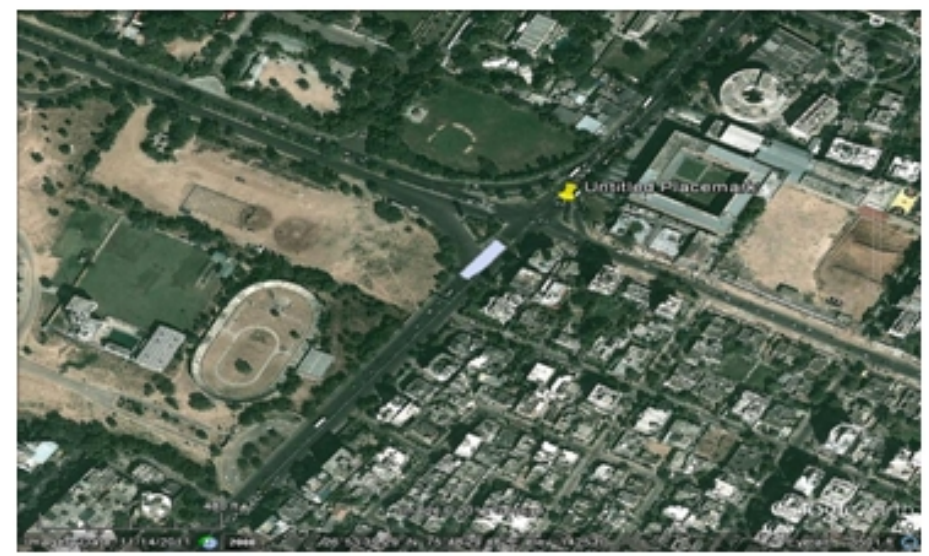

Figure 20

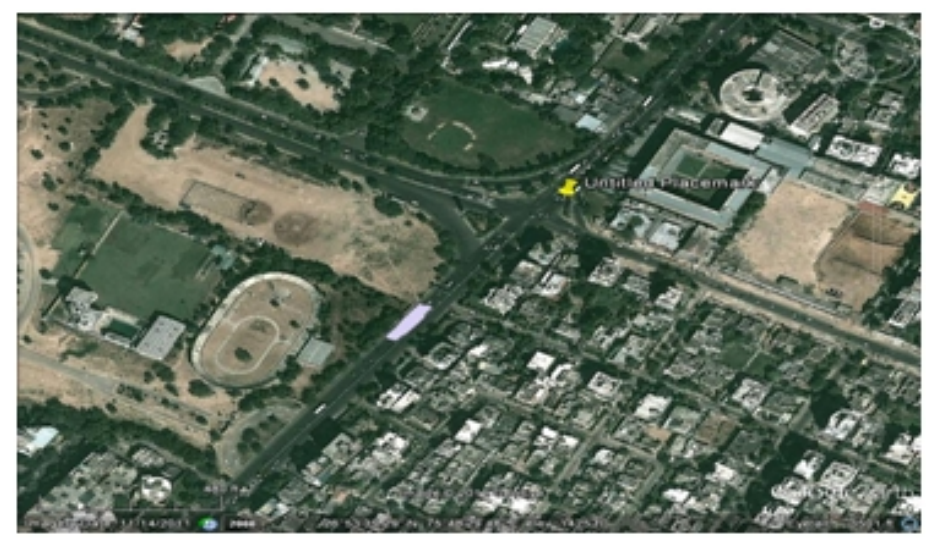

Figure 21 
International Journal of Computer Science \& Information Technology (IJCSIT) Vol 4, No 6, December 2012

Figure 22 shows that the camera will have to take 6 photographs for traffic computation.

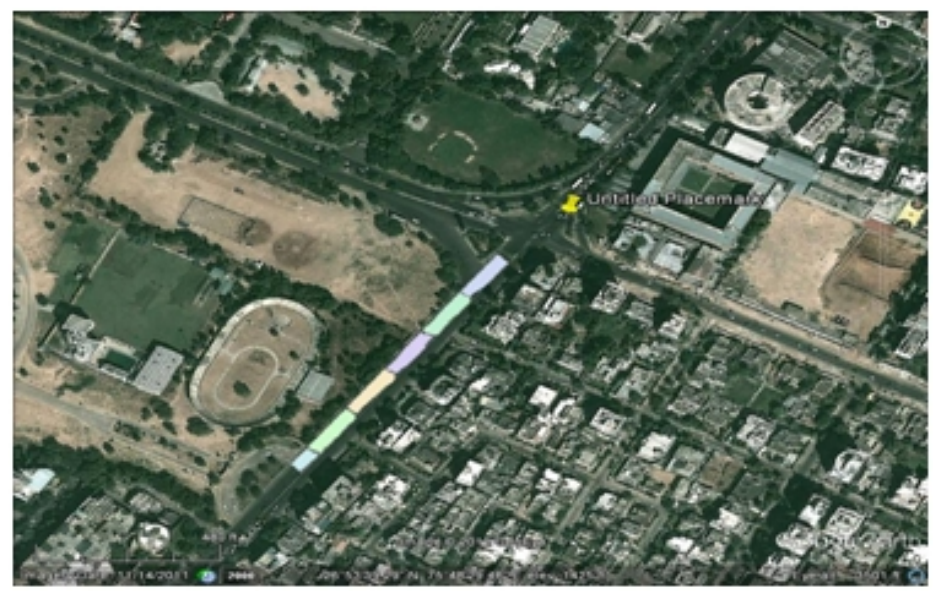

Figure 22

\subsubsection{Considering 50 meters area}

Taking photographs at 50 meter area, CCTV camera covers the following areas.

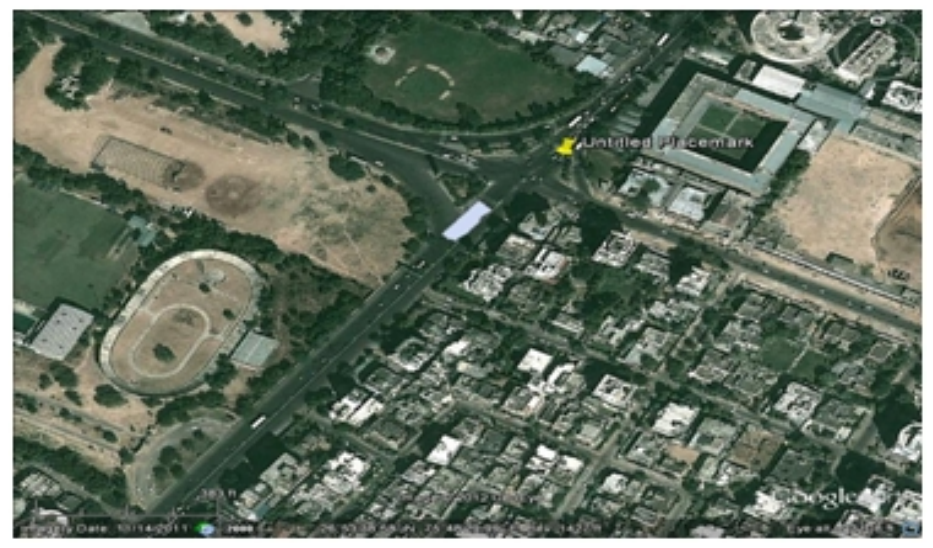

Figure 23

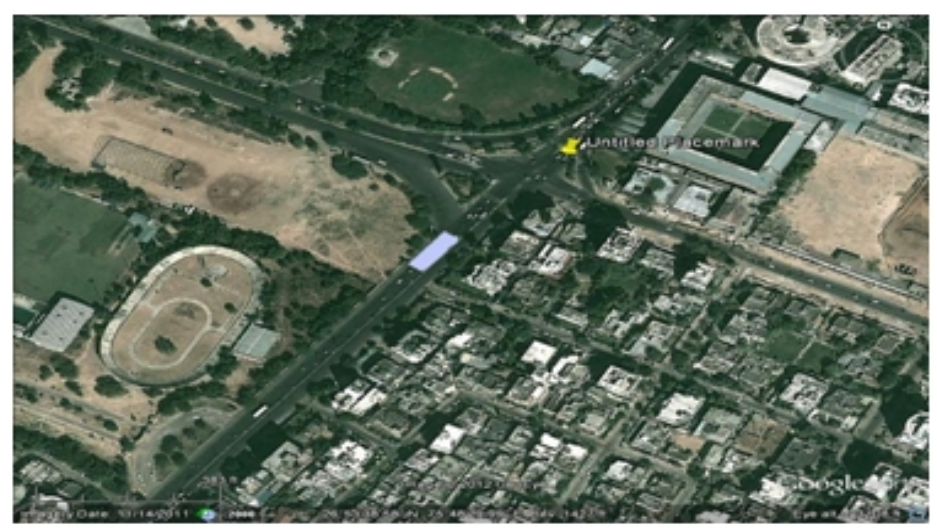

Figure 24 
International Journal of Computer Science \& Information Technology (IJCSIT) Vol 4, No 6, December 2012

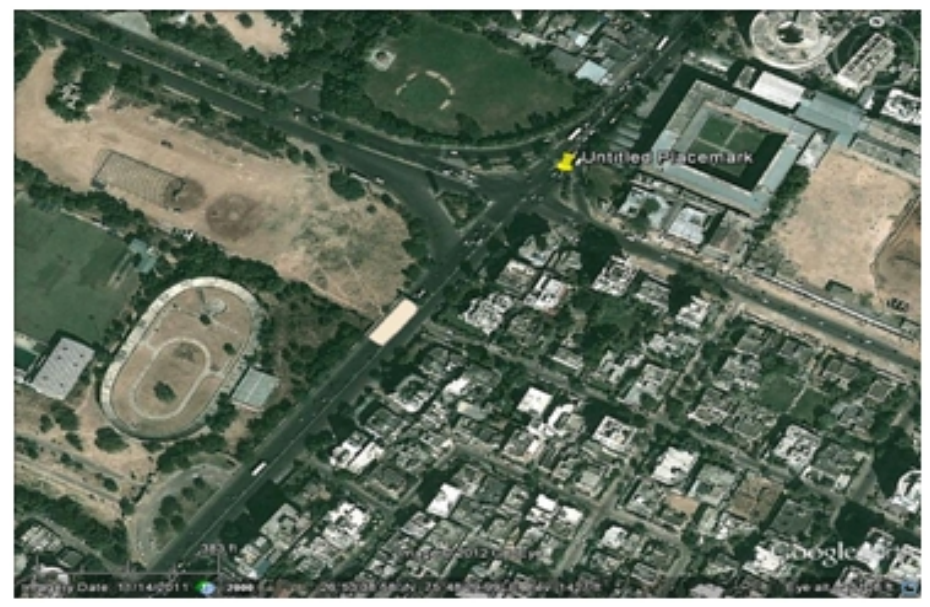

Figure 25

Figure 26 show that the camera will take 6 photos while covering 50 meter of the intersection area.

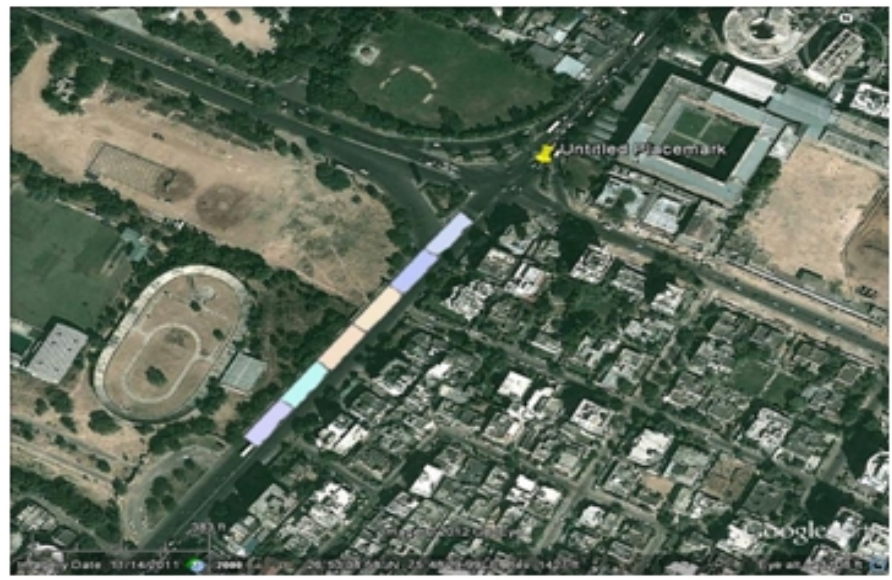

\subsubsection{Considering 100 meter area}

Figure 26

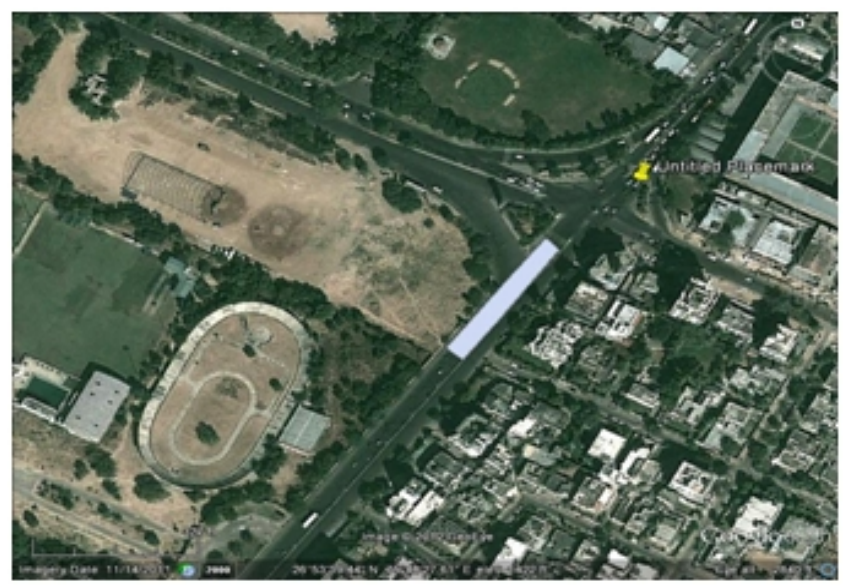

Figure 27 
International Journal of Computer Science \& Information Technology (IJCSIT) Vol 4, No 6, December 2012

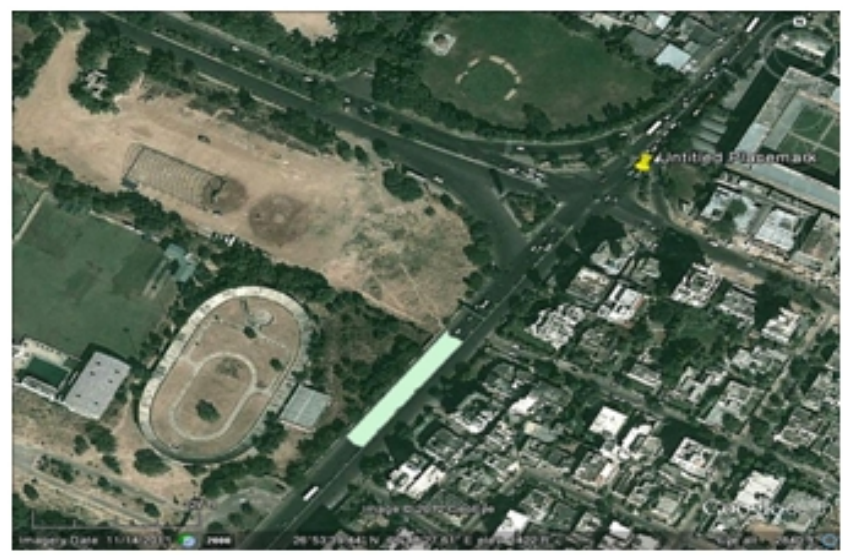

Figure 28

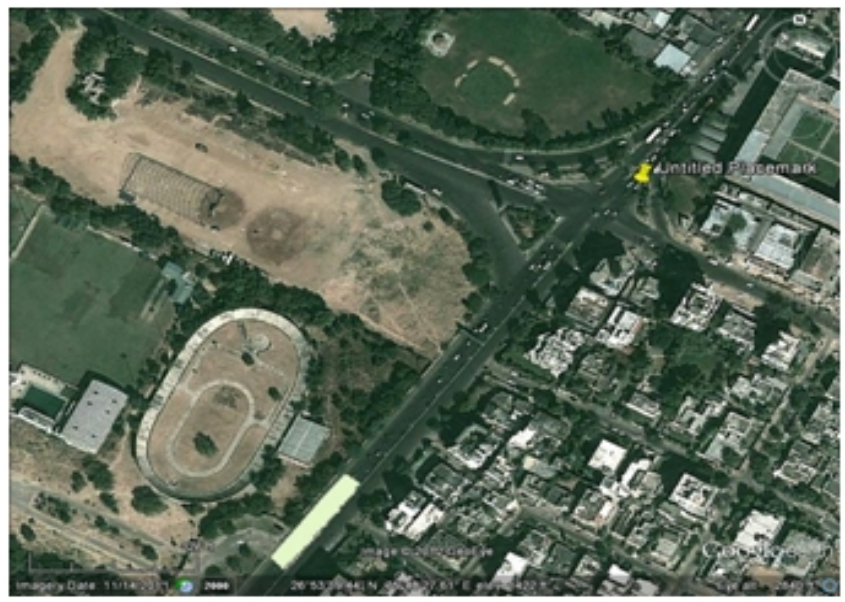

Figure 29

Camera will focus on the road 3 times to cover the complete portion of the required area for traffic computation, as shown in figure 30.

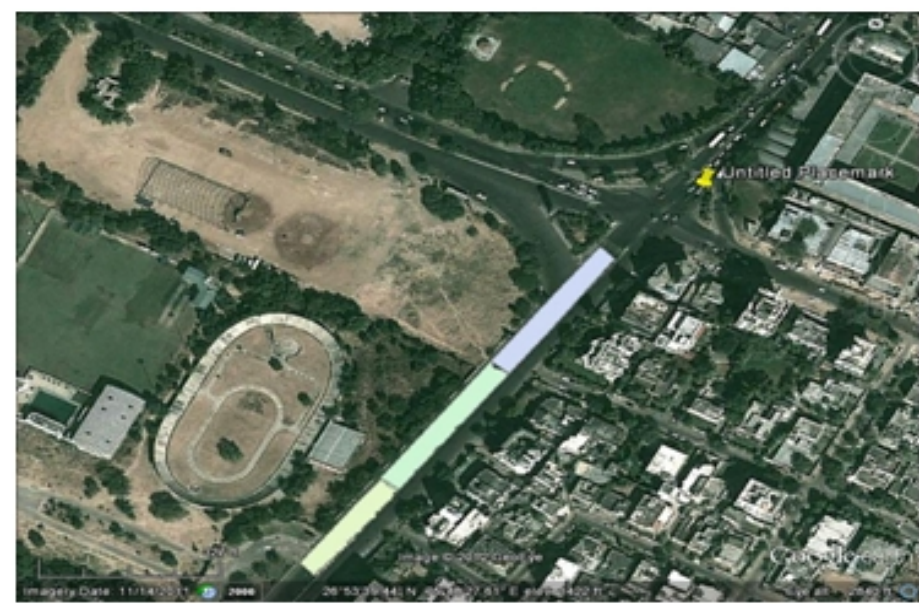

Figure 30 


\subsubsection{Considering 200 meter area}

If the CCTV camera can process 200 meter of the viewing area and compute the traffic, the following images will be captured by the camera.

Figure 31 and 32 show that there will be 2 focus points for the camera to cover the area.

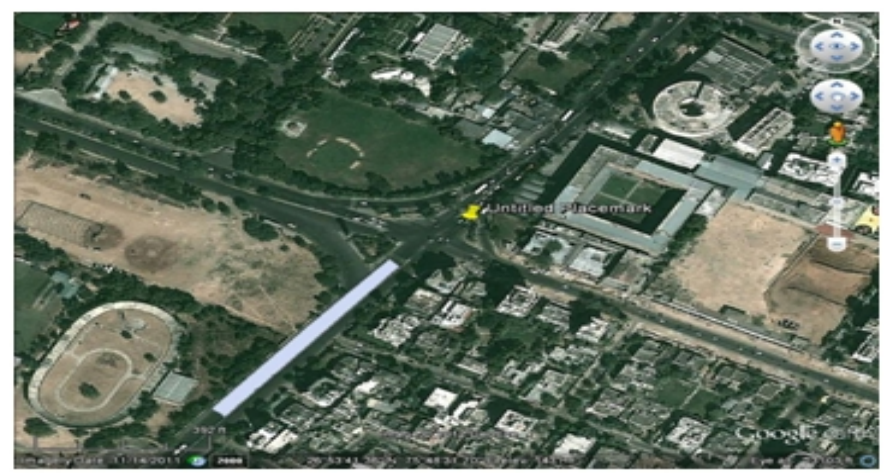

Figure 31

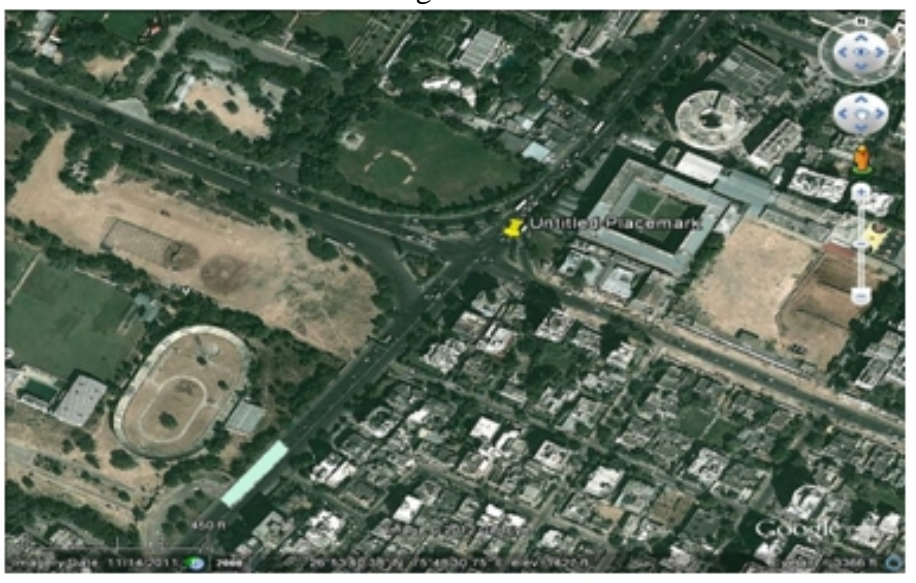

Figure 32

\subsubsection{Considering the complete viewshed}

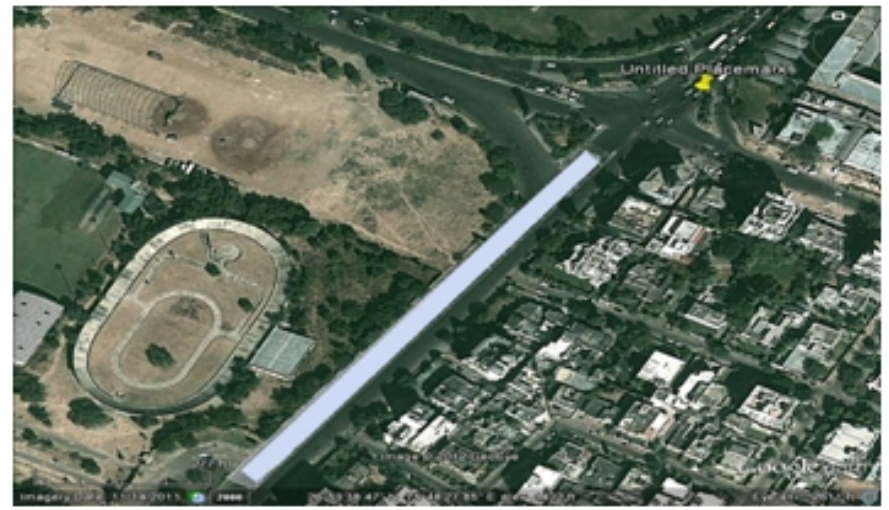

Figure 33

Taking the complete viewshed area, figure 33 shows that the covered area by the camera. 


\subsection{Analysis of results}

The characteristics of the CCTV camera will have to be exploited to determine how much portion of the road will be analyzed for traffic load computation. It is the power of CCTV camera that determines how much area can be viewed correctly so that traffic computation can be done easily on the area. Focus points can be set in a CCTV camera and the number of Focus Points can be from 2-45. The camera takes photos at those focus points at regular interval and so parallel processing of the images can be done to compute traffic load in time. This is a matter of further study that how the images will be processed simultaneously to get the required results of computation.

\section{SIMULATION EXPERIMENT AND RESULTS}

In determining Viewshed, first of all, the height of the camera placement is determined. This is done by setting the parameter OFFSETA in viewshed. The effect of the parameter is monitored and so the value where the best viewshed is available is considered. While talking of the other parameters, they can be adjusted according to the specification of the CCTV camera. The view angle of CCTV affects the parameters AZIMUTH and VERT.

While talking of the CCTV camera, they are available in a number of formats. CCTV camera's characteristics include CCD information, Focus points, Resolution, optical Zoom Ratio etc. These determine the best working of the CCTV camera. CCD size shows what area the camera will cover horizontally and vertically. Inclusion of Optical Zoom in the camera determines how far the camera can view objects easily and properly view without compromising the quality. Focus points show the number of points on which the camera can focus. CCTV Camera with the following characteristics has been assumed:

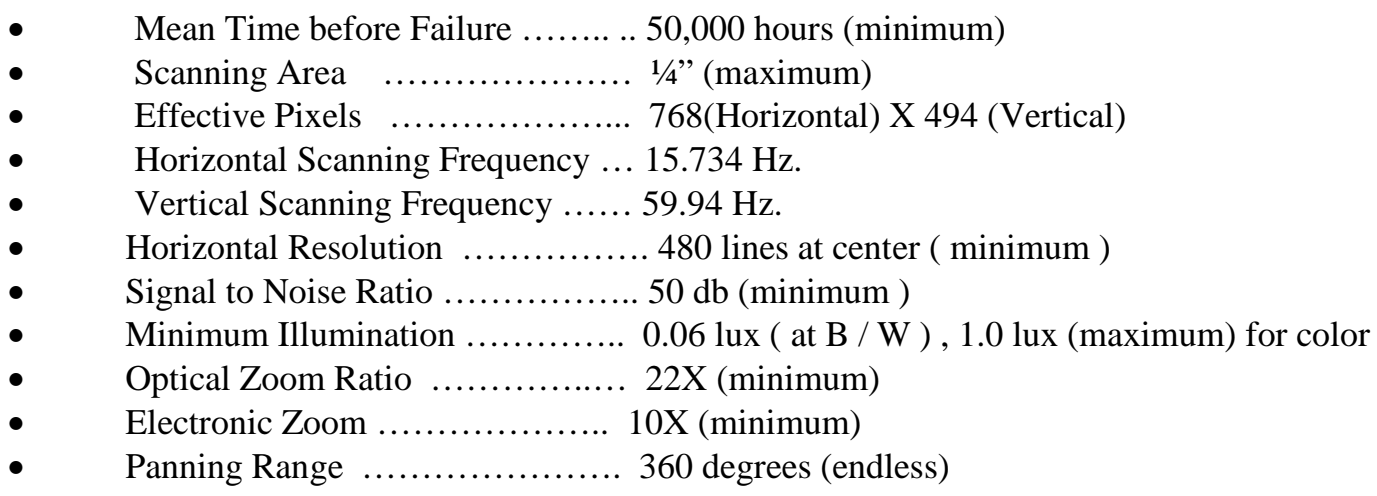

These specifications are of the camera accepted by Colorado Department of Transportation in their wide area traffic surveillance applications [17].

- If the camera covers just 20 meters of the area, it is too less for the complete traffic computation.

- If camera covers the complete intersection part, it becomes difficult for traffic computation as it will be done all at once.

- So the length of the intersection that will be covered should be such that it is easy and fast to perform any calculation regarding traffic computation.

A number of cameras are available that can be used for traffic surveillance purpose. Here, aim is to use the best camera for monitoring so that the calibration of the camera can be very fruitful. 
We assume that the camera has $1 / 4$ " type of CCD. Camera with $795 * 596$ pixels is a good option as it has a large number of pixels that are to be used for image display. A high horizontal resolution like 540 TVL can be considered to make good quality picture. A large optical zoom be taken so that the images can be taken from far off and with the maintained quality. A wide focal length of $3.4 \mathrm{~mm}$ to $119 \mathrm{~mm}$ allows for a range of field of views.

Using the number of pixels in $\mathrm{X}$ and $\mathrm{Y}$ direction, scale factor can be computed. Scale Factor is the ratio: actual covered area on ground by area covered on the image (by the pixels). Scale factor can be computed as:

- Width of the analyzed portion (road of the Rambagh Circle) $=15$ meters.

- $\quad$ Number of pixels in X direction= 795 (from the specifications).

- $\quad$ Converting pixels to centimeter results in $21.03 \mathrm{~cm}$

- So 21.03 centimeter of image covers 15 meter of the actual portion. So scale factor in X direction is $=$ actual $/$ image which comes out to be 71.32 .

- In Y direction, consider number of pixels $=596$ which equals to $15.77 \mathrm{~cm}$ of the photograph.

- $\quad$ Calculating scale factor for the 20 meter portion:

- Scale factor in Y direction(Sy) = actual / image which is 126.82

- $\quad$ Scale factor in $\mathrm{X}$ direction(Sx) remains the same for all the coverage while the scale factor

in $\mathrm{Y}$ direction changes as the distance covered by every coverage is different.

Table 1

\begin{tabular}{|c|c|c|c|c|}
\hline $\begin{array}{l}\text { CCTV Camera } \\
\text { Specifications }\end{array}$ & $\begin{array}{l}\text { Number of } \\
\text { focus points }\end{array}$ & Focus points & $\begin{array}{l}\text { Coverage at } \\
\text { one shot } \\
\text { (meters) }\end{array}$ & Scale Factor \\
\hline \multirow{7}{*}{$\begin{array}{l}\text { E-PTZ-3690 camera } \\
\text { for traffic } \\
\text { monitoring } \\
\text { - } 35 x \text { optical } \\
\text { display } \\
\text { - DSP technology } \\
\text { for highest } \\
\text { quality image } \\
\text { day and night } \\
\text { Automatic and } \\
\text { manual focus } \\
\text { Displays } \\
\text { position of the } \\
\text { camera } \\
\text { direction. } \\
\text { 64 preset } \\
\text { positions } \\
\text { available. }\end{array}$} & 14 & $\begin{array}{l}14 \text { focus points need to be set } \\
\text { in the camera. Photos will be } \\
\text { taken regularly at these focus } \\
\text { points. }\end{array}$ & 20 & $\begin{array}{l}\mathrm{Sx}=71.32 \\
\mathrm{Sy}=126.82\end{array}$ \\
\hline & 9 & $\begin{array}{l}\text { Here, } 9 \text { focus points need to } \\
\text { be set. Points must be such } \\
\text { that they cover continuous } \\
\text { area of the traffic. }\end{array}$ & 30 & $\begin{array}{l}\mathrm{Sx}=71.32 \\
\mathrm{Sy}=190.23\end{array}$ \\
\hline & 6 & $\begin{array}{l}6 \text { focus points can cover } 40 \\
\text { meter or } 50 \text { meter of the } \\
\text { intersection at once. }\end{array}$ & 40 & $\begin{array}{l}\mathrm{Sx}=71.32 \\
\mathrm{Sy}=253.64\end{array}$ \\
\hline & 6 & & 50 & $\begin{array}{l}S x=71.32 \\
S y=253.64\end{array}$ \\
\hline & 3 & $\begin{array}{l}\text { Setting less number of focus } \\
\text { points can make the } \\
\text { computation large and time } \\
\text { taking. }\end{array}$ & 100 & $\begin{array}{l}S x=71.32 \\
S y=634.12\end{array}$ \\
\hline & 2 & $\begin{array}{l}\text { In the case, two photos of the } \\
\text { area will be taken to cover it. }\end{array}$ & 200 & $\begin{array}{l}S x=71.32 \\
S y=1268.23\end{array}$ \\
\hline & 1 & $\begin{array}{l}\text { The middle point of the } \\
\text { complete area will be } \\
\text { considered and computation } \\
\text { be done on just a single } \\
\text { image of the traffic. }\end{array}$ & $\begin{array}{l}\text { Complete } \\
\text { intersection }\end{array}$ & $\begin{array}{l}S x=71.32 \\
S y=1902.35\end{array}$ \\
\hline
\end{tabular}


The scale factor shows the actual image is scale factor times greater than the image recorded by the CCTV camera. A large scale factor shows that a large portion of the road is being viewed while a smaller scale factor shows a small area being covered by the CCTV camera.

If CCTV camera covers a large portion of the intersection area, it is difficult for the computing system to perform any computation regarding traffic. Whereas, if the covered area is too small, the complete computation will take a considerable amount of time to perform the complete calculations as all the images will be analyzed and the total effect will be the combine of all the calculations. So, the coverage of CCTV that is considered optimum is the 50 meter area. This will lead to 6 focus points to be set by the camera.

\section{CONCLUSION}

In this paper, techniques to decide about the camera installation properties for real time traffic signal control have been explored. Viewshed analysis is used to determine what portions of the intersection will be visible. By the various results and the properties of the CCTV cameras, it can be determined how efficiently the traffic can be monitored. The setting can be done so that the camera focuses on different points of the road at different time. With increasing coverage area, number of focus points decrease but scale factor increases. For the camera under consideration, 50 meters coverage area with 6 focus points generate images with scale factor 253.64 in Ydirection.

\section{REFERENCES}

[1] Glick Jonathan (2006) Introduction to ArcGIS. http://julius.csscr.washington.edu/pdf/arcgis.pd.

[2] Map Making in ArcGIS 9.3. Available at: http://www.bgsu.edu/downloads/cas/file91302.pdf.

[3] Exercise on Visibility analysis and Virtual and Landscape Impact Assessment available at: http://geog.hku.hk/gislab/PSDAS_materials/Exercise3_web.pdf.

[4]

http://ww2.wapa.gov/sites/western/transmission/interconn/Documents/hermosawest/viewshedaaal ysis_102309.pdf

[5] http://stanford.edu/ woodsp/natcap/invest/docs/21/aesthetic_quality.html.

[6] Exercise on Viewshed and Cumulative Viewshed Analysis. Available at: http://mapaspects.org/courses/gis-and-anthropology/weekly-class-exercises/week-10-viewshed-andcumulative-viewshed-analysi.

[7] Hobby Andrew (2008). ArcMap and Google Earth.

[8] Mortada K. A., Mohamed K., Merzouki M.A.,” A Descriptive Model For Developing A Hydraulic Geodatabase By Using The GIS Software", International Journal of Computer Science \& Information Technology (IJCSIT), Vol 3, No 2, April 2011

[9] http://www.dnr.state.mn.us/mis/gis/tools/arcview/extensions/DNRGarmin/DNRGarmin.html.

[10] http://free-gis.com/how-to-convert-kml-to-shapefile/17/ .

[11]

http://webhelp.esri.com/arcgisdesktop/9.3/index.cfm?TopicName=Performing\%20a\%20viewshed $\% 20$ analysis.

[12]

http://www.nearby.org.uk/google/circle.kml.php?radius=20m\&lat=26.894825\&long=75.808642\& geomColor=ffffffff.

[13] Yung Nelson H.C, Pang Grantham K.H., Fung George S.K. A Novel Camera Calibration Technique for Visual Traffic Surveillance.

[14] Lee Jay, Stucky Dan (1998). On Application of Viewshed Analysis for determining least cost paths on Digital Elevation Models. International Journal Geographical Information Science, 1998, vol 12, No. 8, 891-905.

[15] Kim Young-Hoon, Rana Sanjay, Wise Steve (2004). Exploring multiple viewshed analysis using terrain features and optimisation techniques. Computers \& Geosciences 30 (2004) 1019-1032.

[16] http://www.cotrip.org/its/whitepapers/CCTV_CAMERA_SPECIFICATION.pdf 